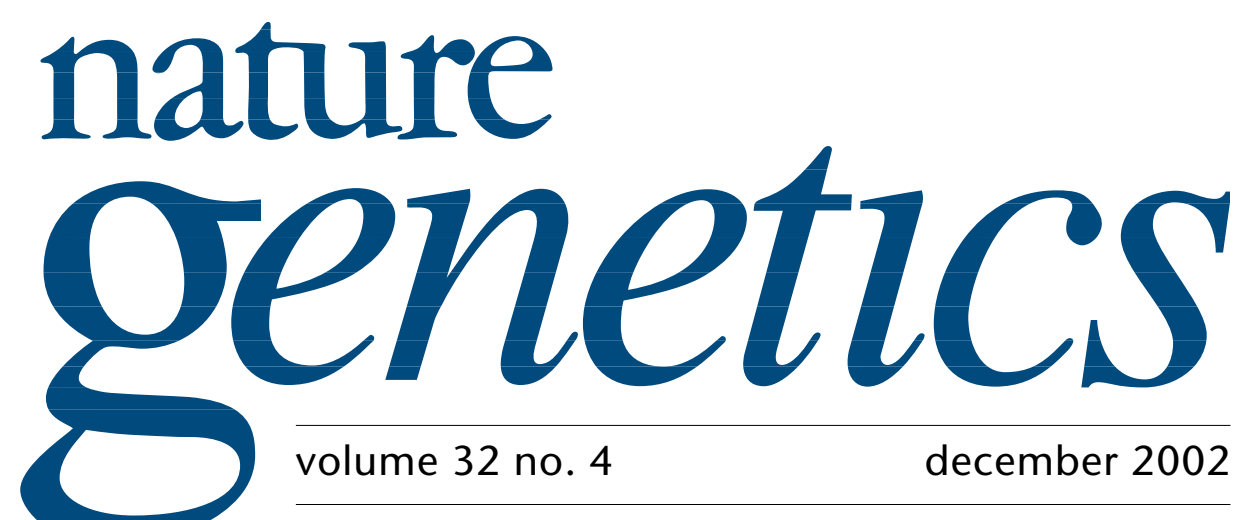

\title{
What's brewing in genetic testing
}

The US Department of Health and Human Services (HHS) recently disbanded at least two expert advisory committees, the National Human Research Protections Advisory Committee and the Secretary's Advisory Committee on Genetic Testing (SACGT). As reported on 17 September in the Washington Post, this decision has prompted some committee members to criticize the move as a politically motivated attempt to ensure that the advice received by officials of the Bush administration is in line with the president's views on these issues. In response, an HHS spokesperson has defended the right of the administration to solicit advice in its own way, and a 23 October announcement in the Federal Register indicates that SACGT will be reconstituted with a much broader mandate (as the Secretary's Advisory Committee on Genetics, Health and Society, or SACGHS). Regardless of the politics, the disbanding of SACGT after three years of work, and in the face of other developments in the area of genetic testing, raises important concerns that should be widely debated.

The 13-member SACGT was chartered in June 1999 by then HHS Secretary Donna Shalala, and began meeting a year later. Chaired by Dr. Edward McCabe of UCLA, SACGT was charged with advising the government on all aspects of the development and use of genetic tests-in particular, the safe and effective incorporation of genetic tests into health care. As a first task, the committee was asked to assess the adequacy of current oversight of genetic tests. In doing so, SACGT addressed the criteria that might be used to assess the risks and benefits of genetic testing, how these criteria might be used to classify tests, the appropriate level of oversight for each kind of test and other related questions.

Possible oversight by the Food and Drug Administration (FDA) was a hotbutton issue for SACGT. To understand why, it is important to realize that the FDA makes a distinction between tests that are manufactured and packaged as kits for sale to multiple laboratories, which are considered diagnostic devices and thus subject to FDA approval, and tests that are developed by individual laboratories themselves and offered directly to consumers (so-called 'home brews'), which are not. Given the increasing number of genetic tests that fall into the latter category, the question of extending FDA oversight to home brews was an obvious one. Anyone who is familiar with the effort to extend FDA jurisdiction to nicotine, however, will recognize that such a move can be extremely contentious, whatever the merits. The members of SACGT, it should be said, were laboring under the 
assumption, widely held, that FDA already had the authority to regulate home brews, and lacked only specific guidelines and the resources to move ahead.

Enhancing the Oversight of Genetic Tests, the SACGT report delivered in July 2000, outlined the committee's substantial progress in dealing with these questions, including the accuracy of genetic tests, their clinical usefulness, the issue of population-based screening and the risks of predictive versus diagnostic tests. These and other parameters were used to develop a scheme for classifying such tests and for determining the level of scrutiny each deserves. Although the committee did not formally recommend their classification scheme, citing "fundamental, irresolvable questions," they did take the important step of proposing that the FDA be given the resources to regulate home-brew tests. In response, Secretary Shalala released a letter indicating that the FDA would indeed develop rules to improve oversight. With the recent decision by current HHS Secretary Tommy Thompson to disband SACGT and establish a new committee, the direction of public policy in this area falls into doubt. Moreover, according to Dr. Joann Boughman, Executive Vice President of the American Society of Human Genetics and member of SACGT, the FDA is now revisiting the basis of their legal authority to regulate these tests.

As the alphabet soup of government acronyms gets thicker, the urgency of coming to grips with the new world of genetic testing increases. Some advances seem relatively straightforward and stand to be beneficial; a case in point is the publication last year of long awaited guidelines for cystic fibrosis screening by the American College of Medical Geneticists. Other offerings, marketed directly to consumers over the Internet, seem rather dubious. A company called Sciona is marketing dietary advice based on an analysis of variation in seven genes involved in free radical damage and detoxification. GeneLink is offering an 'oxidative stress profile' and an 'obestity susceptibility profile' based on the detection of singlenucleotide polymorphisms in relevant genes. To call the predictive value of such tests uncertain and premature would be an understatement.

This is not to say that increased regulation is necessarily the answer to concerns over the impact of poorly vetted genetic tests. Dissenters, including the American Clinical Laboratory Association, argue that the regulatory framework that exists for genetic tests (the Clinical Laboratory Improvement Amendments) is sufficient; that these tests are manufactured with precision; that FDA oversight would prove burdensome and costly; and that the real need is for education of physicians and their patients.

Even if one accepts the argument that manufacturing quality control in the production of these tests is top notch, the impact of 'accurate' results on the behavior of those being tested is not at all clear. The education of physicians is a long-term effort, and the economic incentives for marketing these tests will only increase in the meantime. As a result, although most of the companies offering these tests recommend that consumers seek professional advice upon receiving the results, even well informed physicians will have difficulty interpreting them. Perhaps the most sensible advice-to save one's money-will have come too late.

Regardless of whether the FDA eventually regulates home brews, the decision to disband SACGT seems ill advised. The committee had gathered a great deal of information, solicited public comment and begun to outline the ways in which the clinical utility (not merely the accuracy) of genetic tests could be assessed and used to determine the appropriate degree of regulatory oversight. Joann Boughman has commented, "Comprehensive and inclusive discussion of the complex issues is vital to the design and implementation of good policy and processes". One hopes that the new committee will draw on the invaluable work already done by SACGT, at some expense, and will not shy away from recommending measures to protect consumers when necessary.

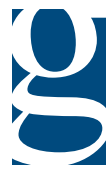

